\title{
Launching Trajectory Planning for the Variable Cross-Section Steel Box Girder
}

\author{
Hong Zhang ${ }^{1}$, Xiaoping Zhang ${ }^{2, *}$, Qiang Guo ${ }^{2}$ and Zhiwu Xue ${ }^{2}$ \\ ${ }^{1}$ CCCC Second Harbor Engineering Company Ltd., 430040, China \\ ${ }^{2}$ CCCC Wuhan Harbor Engineering Design and Research Company Ltd., 430040, China \\ ${ }^{*}$ Corresponding author
}

\begin{abstract}
The incremental launching method has been widely used to construct various kinds of bridges in regions where traffic, geology and topography conditions are limited. Thanks to its excellece on on-site prefabrication, fast assembly and intelligent control, the incremental launching systems are applied in mumerous kinds of bridge construction projects. However, most of the bridges are successfully built without having the obvious curve features on working interfaces. This paper mainly proposed an adaptive incremental launching method for the Dongfeng Avenue freeway $\mathrm{L} 7 \mathrm{89} \mathrm{m}$ viaduct launching project, to which the traditional incremental launching method is hard to be applied. Firstly, the construction background is firstly introduced. Then, the corresponding launching trajectory is planned according to the continuous variation of curve features of the working interfaces. To realize the launching trajectory, the control stratege and kinematic conditions of multi-point on-site incremental launching devices are described. Further, the application and verification of the launching construction are analized and discussed. Finally, the proposed new incremental launching method and the results of trajectory planning for the variable cross section steel box girder are concluded.
\end{abstract}

Keywords-incremental launching; bridge girder; launching trajectory; curve feature

\section{INTRODUCTION}

The Incremental Launching method [1-3] is a bridge superstructure construction technique that uses multi-point IL devices to continuously launch bridge girder segments to its designed final pose. The bridge girder segments are manufactured in local or nearby factory and transported to the construction site in terms of vehicles or ships. With the help of the temporary guiding nose [4] pre-weld on the first segment, the bridge girder is capable of being continuously launched by the IL system and intermittently assembled till the whole girder is launched in place [5-7].

Often, there are even number of IL devices that assembled on the structural pies or temporary pies. In terms of the multipoint static contacts among the working interfaces of bridge girder and flexible IL devices, the IL system provides a much more stable and controllable construction condition than using dragging-type launching method. The on-site IL device simultaneously works together with others with independently hydraulic and control systems. Owing to its stiffer and compact features, the IL device's launching movement is barely affected by factors from the construction environment, vise versa. Thus, the IL method is widely used for various kinds of bridge construction [8-10] in urban, canyon, the regions across rivers and offshore where traffic, geology and topography conditions are limited.

The most representative application was the construction of Millau viaduct in France [11-13], as shown in Figure I. The bridge girder is launched by using the wedge-type launching system. The mechanical movement is generated by the sliding motion between a pair of high precision wedge blocks. Then, the bridge girder is launched through a lifting-pushing coupled motion achieved by multi-point WL devices. However, the sliding motions at multiple launching stations is not capable of providing the adaption to the launching adjustment in horizontal plane and to the curve features of the launching interface. Further, the on-site WL device has a quite large structure dimension that demands larger and stiffer piers and is not suitable for the launching construction in urban where space is limited.
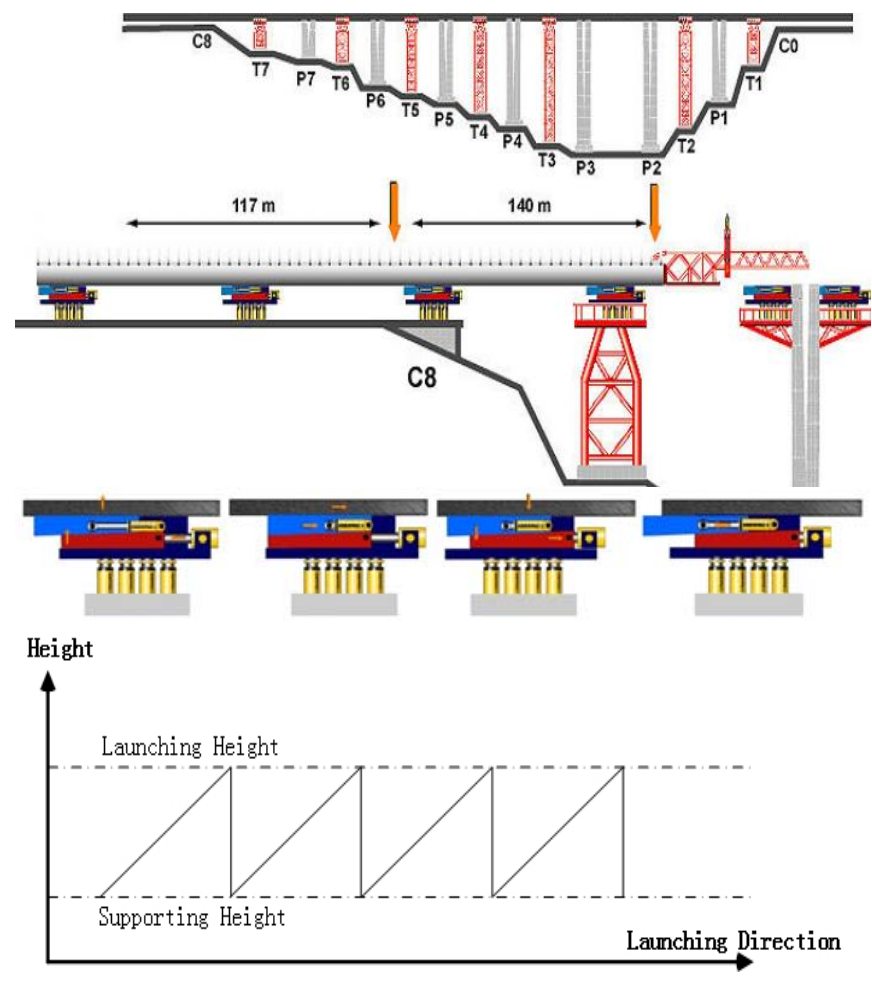

FIGURE I. WEDGE-TYPE LAUNCHING CONSTRUCTION OF MILLAU VIADUCT AND CORRESPONDING LAUNCHING DEVICE

In 2009, a walking-type launching device [14-18] is developed and successfully applied in the construction of 
Jiubao bridge in China, as shown in Figure I. Jiubao bridge is a three-span beam-arch composite bridge across the Qiantang river with the length of $1855 \mathrm{~m}$. Up to $20 \mathrm{IL}$ devices are used to complete the launching construction. The IL device is designed to have the independent motions function that is capable of launching the bridge girder in Cartesian space without coupled mechanisms or complicated hydraulic transmission systems. The launching motions are decomposed as lifting, pushing, dropping and returning. Then, the bridge girder follows a rectangular launching trajectory till the reaching the final position, as shown in Figure II. Later, this walking-type of IL system are widely used in many other launching project, such as the constructions of Luozhou bridge, Ruan Jiangxi bridge, Erqi Yangzte bridge and etc. Still, to a large extent, the adaption to the geometric features of the launching interface is still affected by its large structure dimension, as well. So to speak, the launching method and its IL devices are friendly use only in the condition that the working interfaces of the bridge girder is flat or nearly flat.
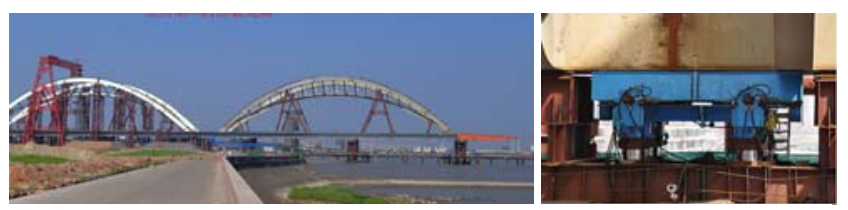

Height

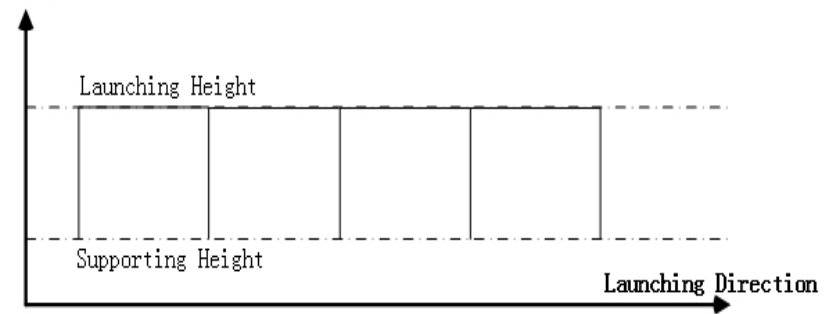

FIGURE II. WALKING-TYPE LAUNCHING CONSTRUCTION OF JIUBAO BRIDGE, INCREMENTAL LAUNCHING DEVICE AND GIRDER LAUNCHING TRAJECTORY

In order to launch the bridge girder, the launching interface of which has the curvature features, a novel IL method should be proposed. An adaptive launching interface and height adjustment function have to be satisfied for the multi-point onsite IL devices as well. Once the IL device is capable of 6-DoF adapt to the local curve feature of the girder and has the ability to get into contact with bottom surface of the girder, the accuracy of launching movements are easily achieved with the help of the PID control algorithm. The influence of the height change of the girder will not be affected by the IL systems. Sequentially, it leads to the completion of the launching trajectory for every launching iteration. Hence, apart from the difficulty to satisfy the synchronicity of multi-point IL devices, which can be solved in terms of applying the close-loop control algorithm and corresponding control units, the remaining problem is the launching trajectory planning and construction control strategy design.

\section{PROJECT BACKGROUND}

As shown in Figure III, Dongfeng avenue freeway viaduct is a typical continuous composite beam-steel bridge. The viaduct starts from the Wangjiazui overpass bridge in the north, and ends to the intersections of Wuhan No.3 expressway in the south, the total length of which is $5,808 \mathrm{~km}$. The L7 span of the viaduct is located above an old bridge across the Xinmin River, the layout and the construction site of which is shown in Figure III. The L7 span of the viaduct is $89 \mathrm{~m}$, the bridge girder of which is made up by a total 2200 tonne viable cross section steel box girder. The U-shape sbg is composed of 9 segments, L7-6 to L7-14. There is a $2 \%$ slope in the transverse direction, and the radius of its bottom surface in vertical plane is $750 \mathrm{~m}$ with a difference in height from $2.6 \mathrm{~m}$ to $3.8 \mathrm{~m}$.

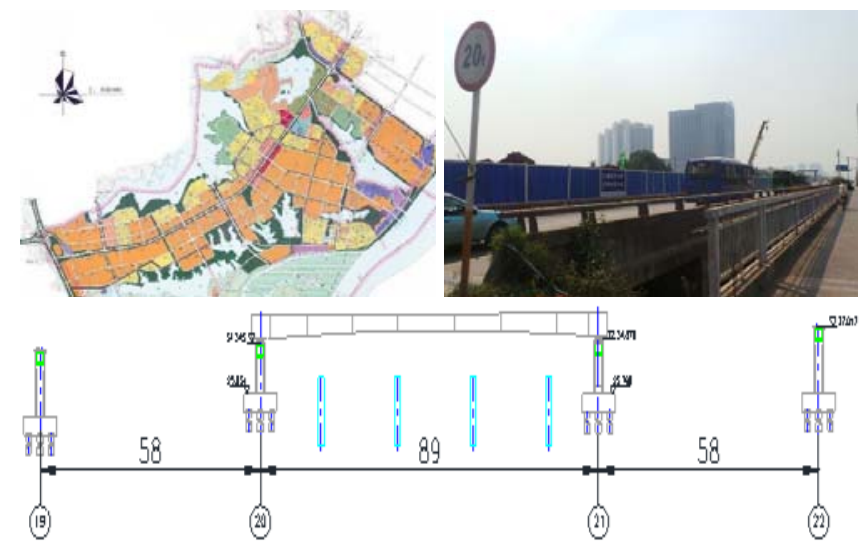

FIGURE III. OVERVIEW OF DONGFENG AVENUE VIADUCT CONSTRUCTION ON XINMIN RIVER BRIDGE AND GENERAL LAYOUT OF DONGFENG AVENUE FREEWAY VIADUCT L7

To safely and efficiently construct the L7 span of the viaduct, option plans have been considered. By using several 260 tonne mobile cranes, the sbg segments can be lift up by a maximum 25.7 tonne bearing capacity with cantilever length of $36.3 \mathrm{~m}$. However, using the mobile crane would lead to the fully occupation of the construction site and blocking of the traffic. Meanwhile, the construction of L7 span of the viaduct is right on the old Xinmin river bridge, the structure form of which is simple supported $\mathrm{T}$ beam. The old bridge is not capable of supporting multiple mobile cranes that weighting more than 20 tonne. Further, the degree of automation of mobile crane lifting is relatively low, and the construction efficiency and safety are not guaranteed.

Another commonly used method is applying the bracket erecting structures and large tower crane. Using this method, to certain extent, eases traffic pressure during the construction period. Yet, the preparation and applying of these facilities would lead to the increasing cost of temporary structures and overload of old bridge as well.

The same situation would be faced if using dragging-type launching method. A slipping platform and simple Steel pipe pile bracket structure will be built before the launching construction. Multiple winches are used to accomplish the dragging movements of sbg, which would result in the generation of large horizontal forces and difficulties of dragging movement control.

Taking the safety, efficiency and construction conditions into comprehensive consideration, IL method is applied. Still, the traditional IL method and its corresponding systems often used to launch the bridge girders which often have flat 
curvature working interfaces. Namely, the traditional multipoint on-site IL devices escape from the variation change of curve features during launching construction. The sbg follows a fixed rectangular trajectory until the last iteration of launching sequence.

In view of the defects stated above, an innovative IL method and related launching system are proposed. According to the curvature of L7 span of the viaduct in vertical and transverse direction, in the remaining part of paper, we plan the launching trajectory of for the variable cross section sbg and multi-point on-site IL devices. The control strategy and realization of the IL device to fine satisfy the requirements of launching trajectory is also described. Moreover, the launching construction under the designed launching trajectory is fully verified. Finally, the proposed IL method and the launching trajectory for the construction of L7 span of Dongfeng avenue viaduct is discussed and concluded.

\section{TRAJECTORY PLANNING}

In order to fine launch the variable cross section sbg in Dongfeng Avenue L7 span construction project, launching trajectory planning is designed. Totally 37 launching steps are designed to complete 22 launching conditions.

To better accomplish the launching construction, traditional and an innovative launching strategy are considered. The traditional launching method is as the ones that stated in the previous sections. The multiple IL devices are actively adapt to the curve surface of sbg that the launching trajectory is a nominally line through the launching direction. In this case, the maximum $1.2 \mathrm{~m}$ height different is supposed to be compensated by large number of height adjustment jacks at each launching platforms. Then, the bridge girder is launched according to the zero-position of the supporting jacks which would potentially increase the launching height during the construction and consequently leads to the risks of launching.

Therefore, an innovative launching strategy is proposed. The launching height of the bridge girder is continuously changed throughout the entire launching process, in the condition of which, the girder is capable of passive adapting to the height of the IL devices at each launching platforms within the launching stroke. In addition, height adjustment devices are designed and assembled in the bottom of the supporting platforms to increase the DoF and adjustment capability in height directions, which is shown in Figure IV.
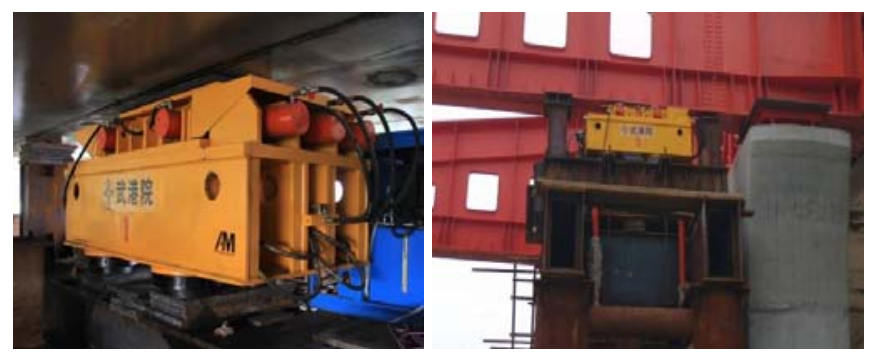

FIGURE IV. IL DEVICE, IN ORANGE, TOGETHER WITH HEIGHT ADJUSTMENT JACKS, IN RED, ARE ASSEMBLED IN THE BOTTOM OF THE SUPPORTING PLATFORMS TO ADJUST THE HEIGHT OF LAUNCHING PLATFORMS
In terms of applying the launching strategy of 'girder passive adapt to IL devices', the overall safety and feasibility of launching construction are guaranteed. Firstly, the guiding nose truss is assembled on site and hoisted to be welded with L7-6, together with which L7-7 and L7-8 are manufactured on the assembly platform. The initial nose-girder structure is supported by IL devices or supports on launching platforms \#1, \#2 and assembly platform. By carefully computing the bearing forces of each IL devices and measuring the positions sbg, the continuous launching process are planned. L7-9 to L7-14 segments are intermittently welded onto the girder after several launching iterations finished. The steps are specifically planned, in which the guiding nose are starting to get into touch with the new launching platforms and the IL devices are preparing to be transferred on them. Selected incremental launching steps are depicted in Figure V.

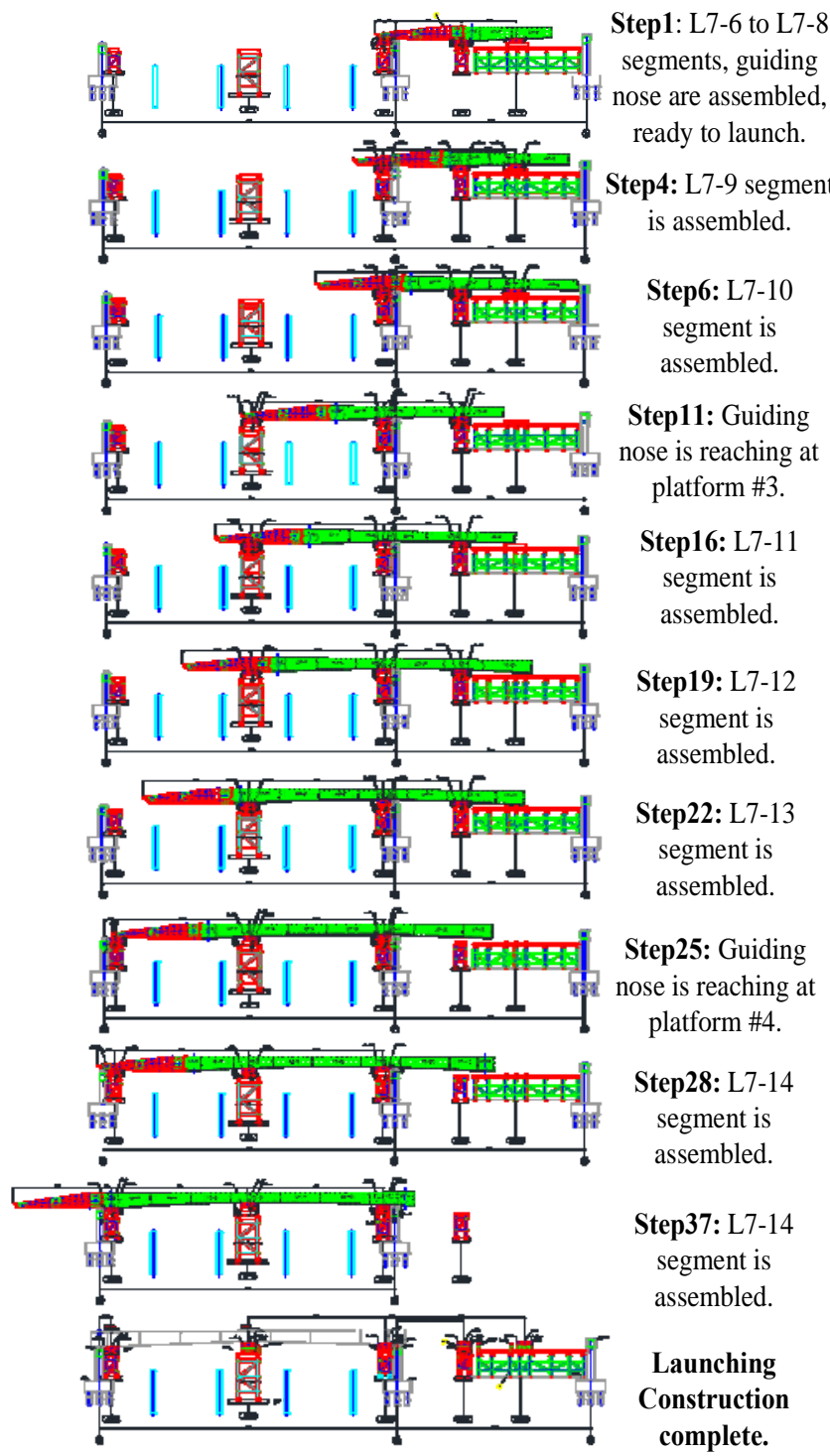

FIGURE V. IL DEVICE, IN ORANGE, TOGETHER WITH HEIGHT ADJUSTMENT JACKS, IN RED, ARE ASSEMBLED IN THE BOTTOM OF THE SUPPORTING PLATFORMS TO ADJUST THE HEIGHT OF LAUNCHING PLATFORMS 


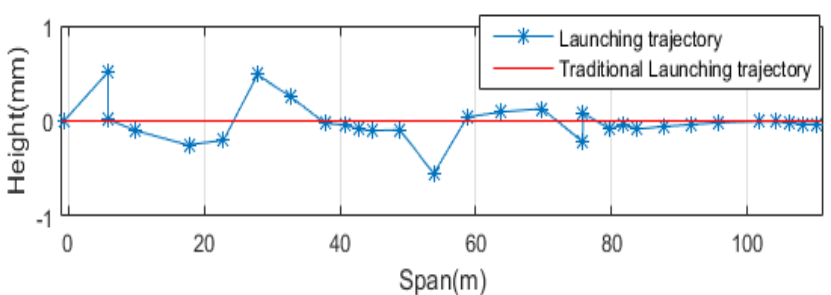

FIGURE VI. LAUNCHING TRAJECTORY OF DONGFENG AVENUE L7 SPAN

The launching trajectory is described in Figure VI. The trajectory turns out to be a wave-type path in vertical plane, rather than the horizontal line that planned by means of using the traditional launching method.

\section{REALIZATION OF LAUCNHING CONSTRUCTION}

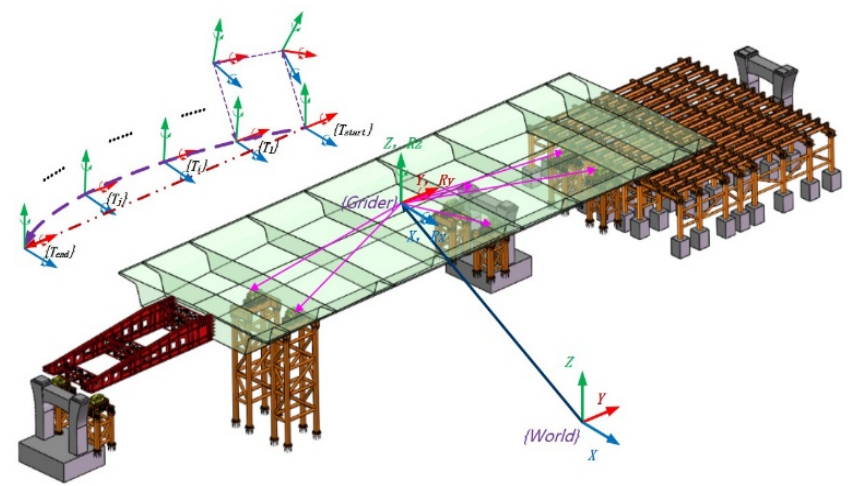

FIGURE VII. KINEMATIC RELATIONSHIP BETWEEN THE SBG GIRDER AND IL DEVICE ON EACH LAUNCHING PLATFORM, THE

LAUNCHING TRAJECTORY SHOWS IRREGULAR LAUNCHING MOTIONS FOR EACH IL DEVICE

After proper planning the launching trajectory, the launching construction is implemented in terms of computing the kinematic relationship between the pose of girder and multi-point IL devices. As shown in Figure VII, the sbg girder is assumed to be a rigid body, and the position ${ }_{W} \mathbf{p}^{w, c_{i}}$ and ${ }_{W}^{C_{i}} \mathbf{R}$ orientation, namely the pose of every IL device, are described as:

$$
\begin{gathered}
{ }_{W} \mathbf{p}^{w, G_{i}}={ }_{W}^{G} \mathbf{R}_{G} \mathbf{p}^{g, C_{i}}+{ }_{W} \mathbf{p}^{w, g} \\
{ }_{W} \mathbf{p}^{w, G_{i}}={ }_{W}^{G} \mathbf{R}_{G} \mathbf{p}^{g, C_{i}}+{ }_{W} \mathbf{p}^{w, g}
\end{gathered}
$$

where ${ }_{W} \mathbf{p}^{\mathrm{w}, g},{ }_{G} \mathbf{p}^{g, c_{i}},{ }_{W}^{G} \mathbf{R}$ and ${ }_{G}^{C_{i}} \mathbf{R}$ are the positions and orientation of sbg girder and the $i$ th IL device with respect to the world frame $\{\mathbf{W}\}$ and girder frame $\{\mathbf{G}\}$, respectively.

Considering the infinitesimal displacements of the bridge girder $\left[{ }_{w} \delta \mathbf{P}_{g}^{T}{ }_{w} \boldsymbol{\delta}_{g}^{T}\right]^{T}$ which is measured and controlled by the distributed PLC control units and affected by the uncertain factors from the construction site, the infinitesimal movements of the ith IL device $\left[{ }_{w} \delta \mathbf{P}_{c_{i}}^{T},{ }_{w} \delta \boldsymbol{\theta}_{c_{i}}^{T}\right]^{T}$ is derived as follow:

$$
\begin{gathered}
{\left[\begin{array}{c}
{ }_{w} \delta \mathbf{P}_{c_{i}} \\
{ }_{w} \delta \boldsymbol{\theta}_{c_{i}}
\end{array}\right]=\mathbf{J}_{g}\left[\begin{array}{c}
{ }_{w} \delta \mathbf{P}_{g} \\
{ }_{w} \delta \boldsymbol{\theta}_{g}
\end{array}\right] \mathbf{J}_{c_{i}}^{-1}} \\
\mathbf{J}_{g}=\left[\begin{array}{cc}
\mathbf{I} & -{ }_{w} \mathbf{p}^{g, c_{i}} \otimes \\
\mathbf{O} & \mathbf{I}
\end{array}\right]=\left[\begin{array}{cc}
\mathbf{I} & -{ }_{W}^{G} \mathbf{R}_{g} \mathbf{p}^{g, c_{i}} \otimes \\
O & \mathbf{I}
\end{array}\right] \\
\mathbf{J}_{c_{i}}=\left[\begin{array}{cc}
C_{i} \mathbf{R} & -{ }_{W} \mathbf{p}^{W, c_{i}} \otimes \\
\mathbf{O} & { }_{W}^{C_{i}} \mathbf{R}
\end{array}\right]=\left[\begin{array}{cc}
{ }_{W} \mathbf{R} & -{ }_{W}^{C_{i}} \mathbf{R}_{c_{i}} \mathbf{p}^{W, c_{i}} \otimes \\
\mathbf{O} & { }_{W}
\end{array}\right]
\end{gathered}
$$

where $\mathbf{J}_{g}$ and $\mathbf{J}_{c_{i}}$ are the jacobian matrices of small displacement of sbg girder and the ith IL device, respectively.

In terms of executing the adaptive lifting up, pushing forward, lowering down and resetting movements [16], which is fine controlled by the self-tuning PID iterative algorithm, the launching trajectory of each IL device follows the irregular quadrilateral motions. The specific launching motions are the results of uncertainties coming from factors such as the launching errors in transverse directions, inaccurate or false assembly of launching platform or IL devices, the local elastic deformation of sbg girder, and etc.

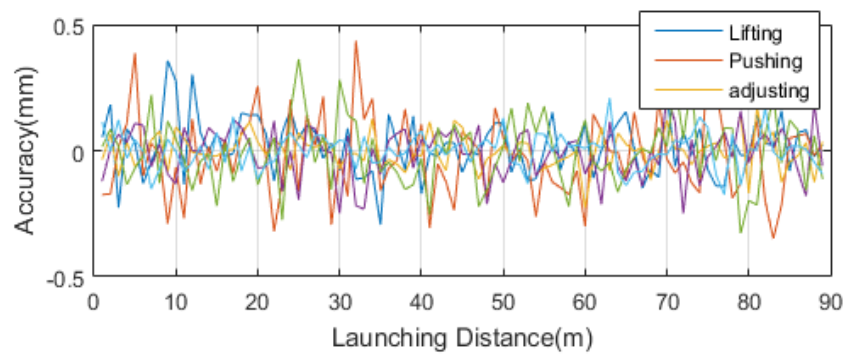

FIGURE VIII. THE ACCURACY OF SYNCHRONOUS LAUNCHING MOVEMENTS

Therefore, the synchronization performance of all IL devices are guaranteed by carefully computing and controlling the kinematic relationships. Through construction practice, the accuracy of the synchronous launching is within $1 \mathrm{~mm}$, and is shown in Figure VIII. Consequently, the launching trajectory of sbg girder is fully controlled and accomplished.

\section{LAUNCHING CONSTRUCTION VERIFICATION}

The main purpose of fine planning the launching trajectory is to ensure the safety of the launching construction. The bridge girder of L7 span of the viaduct is made up with 9 welded segments sbg with different cross sections, the stress concentration and stiffness control of which need more concern than that of concrete made girders.

According to GB/T 3811-2008, the load for the verification of girder's strength during launching construction should be 
the maximum load combination. The main load of the bridge girder includes the weight of each segment, which is listed in TABLE I, the 669KN temporary guiding nose and the downward blowing wind load. Referring to GB50009-2012, the wind load is computed as:

$$
w_{k}=\beta_{g z} \mu_{s} \mu_{z} w_{o}=0.154 K N / m^{2}
$$

where $w_{k}$ is the standard value of wind load, $\beta_{g z}=2.05$ is the vibration coefficient of wind at height of $\mathrm{z}=15 \mathrm{~m}, \mu_{\mathrm{s}}=1.0$ is the shape coefficient of the wind load, $\mu_{z}=0.65$ is the height coefficient of wind pressure. $w_{o}=v^{2} / 1600=0.1156$ is the basic wind pressure, $v=13.6 \mathrm{~m} / \mathrm{s}$ is the level- 6 gusts velocity at type-c area.

TABLE I. WEIGHT OF BRIDGE GIRDER IN SEGMENTS (UNIT IN KN)

\begin{tabular}{|c|c|c|c|c|c|c|c|c|c|}
\hline SEG. & L7-6 & L7-7 & L7-8 & L7-9 & L7-10 & L7-11 & L7-12 & L7-13 & L7-14 \\
\hline Weight & 2879 & 1987 & 1956 & 2236 & 2878 & 2281 & 2452 & 1727 & 2879 \\
\hline Total & \multicolumn{8}{|c|}{21275} \\
\hline
\end{tabular}

To evaluate the loading conditions, ANSYS is applied for the quasi-static FEA simulation. The sbg is configured as the Q345 steel, the density and elastic modulus of which are 7.98tonne $/ \mathrm{m}^{3}$ and 206Gpa, respectively.

The whole launching process is divided as 22 construction conditions, all of which are analyzed to evaluate strength and stiffness of the sbg and to determine whether the planned launching trajectory is suitable.

As shown in Figure IX and Figure X, the stress states of the sbg during launching are continuously within the tolerance. The peak stresses appear in conditions 8, 11, 17 and 20, and the maximum stress is $97.899 \mathrm{Mpa}$ with safety factor $s=[\sigma] / \sigma_{\max }=1.7876$. In condition 8 , the temporary guiding nose starts to get into touch with the \#3 launching platform, the reaction force form changes. In condition 11, L7-11 segment is welded on the assembly platform, bridge segments between guiding nose and L7-8 are supported by the 4 IL devices on platform \#2 and \#3, the joint of the guiding nose and L7-6 is under bearing moment. In condition 20, the same situation happens when L7-14 is welded on the assembly platform. For the rest of the conditions, the stress states are comparably stable that the launching trajectory for the construction is well planned without the generation of local stress concentration.

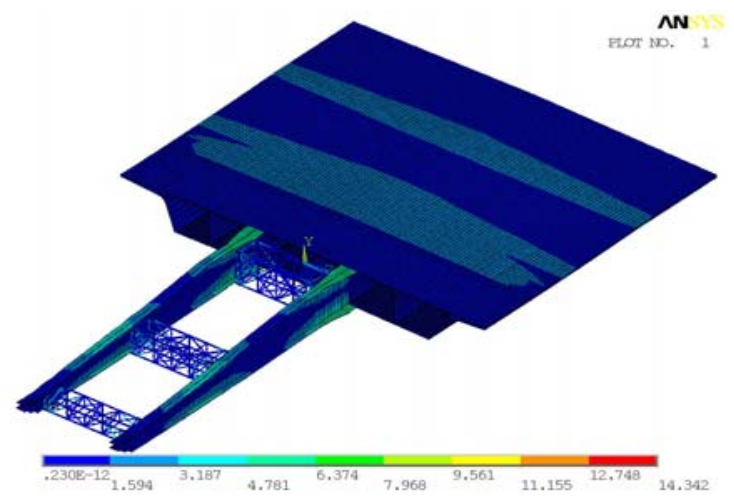

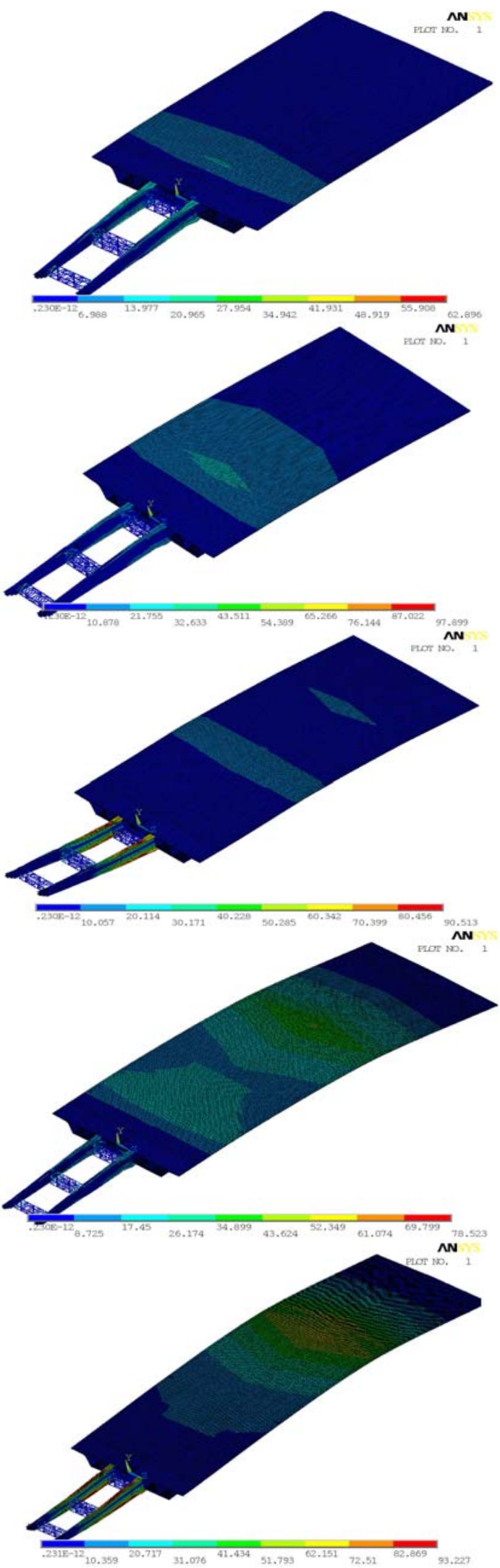

FIGURE IX. SIMULATION OF STRESS IN LAUNCHING CONSTRUCTION CONDITION 1, 6, 8, 11, 17, 20 

Further, as shown in Figure XII and Figure XIII, the maximum displacement of the sbg during launching are continuously within the tolerance. The peak displacement appear in conditions 8, 16 and 20, the maximum displacement is $196.829 \mathrm{~mm}$ which is within the boundary of $236.9 \mathrm{~mm}$. In condition 16, L7-13 segment is cantileveredly welded on the assembly platform. The weight of the new segment leads to a $168.513 \mathrm{~mm}$ deflection at the end of the sbg, which is linear reduced under the process of launching construction. In condition 20, the same situation happens when L7-14 is welded on the assembly platform, the peak displacement of whole launching construction is generated at the end of the last segment. For the rest of the conditions, the displacement are almost linear changed and are comparably stable which means the launching trajectory is reasonably planned.

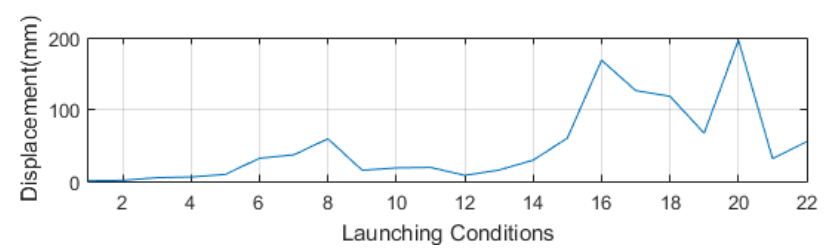

FIGURE XIII. THE MAXIMUM DISPLACEMENT OF SBG DURING 22 LAUNCHING CONSTRUCTION CONDITIONS

\section{LAUNCHING CONSTRUCTION VERIFICATION}

In this paper, we prosposed an new type of launching trajectory planning and its application in term of considering the curve features of the variable cross section steel box girder in the launching construction of 89m Dongfeng avenue L7 viaduct. Due to the defects of unable to adapt the curvature of the working interface of sbg, traditional IL method is only applicable for the flat-bottom girder launching construction. By considering the construction conditions, the launching trajectory is planed in details. In addtion, the kinematic condition among IL devices and sbg is analyzed to better satisfy the accuracy and stability of launching construction. The stress and displacement conditions of sbg during launching are evaluated and verified as well. The proposed new IL method and its trajectory planning for the variable cross section steel box girder are successfully applied in practice.

\section{ACKNOWLEDGMENT}

This work is supported by research and development projects of CCCC Second Harbor Engineering Company Ltd., which are "Special equipment Intelligent Monitoring System" and "The Visual Pose Control System of Incremental Launching Devices”. Also, the authors would like to thank the Sixth Subsidiary of CCCC Second Harbor Engineering Company Ltd., and its engineers for their kind help and advice on launching construction.

\section{REFERENCES}

[1] R. Marco, “Bridge Launching, Thomas Telford,” London, 2002.

[2] C.Y. Shao, "Key technological study of long span continuous composite box girder bridges,” PhD. Thesis. Tongji Univ., 2007.
[3] W. Zellner, H. Svensson, "Incremental Launching of structures,” ASCE. J. Struct. Eng. Vol. 0733-9445. 109:2, pp. 520-537, 1983.

[4] A. N. Fontan, J. M. Diaz, A. Baldomir and S. Hernandez, "Improved optimization formulations for launching nose of incrementally launched prestressed concrete bridges,” ASCE. J. Bridge Eng. Vol. 1943-5592. 000016916, pp. 461-470, 2011.

[5] H. Huang, L. Zhang, Z. Tian, "Analysis of secondary internal force for oblique continuous beam in the process of incremental launching,” J. GZ univ. Nat. \& Sci. vol. 27(3), pp. 126-129, 2010.

[6] R. June, U. Heymel, K.H. Reintjes, O. Schreiber, "Application of prefabricated sections for composite bridges shown on the example of Bahretal Bridge,” Stahlbau. Vol. 78(6), pp. 385-393, 2009.

[7] J.F. Wang, J.P. Lin, R.Q. Xu, "Incremental launching construction control of long multispan composite bridges,” ASCE. J. Bridge Eng. Vol. 1084-0702. 04015006, pp. 1-9, 2015.

[8] B. Kisch, P. Langefors, "Incremental launching versus Scaffolding for construction of Prestressed concrete bridges,” Mast. Thesis. Chalmers Univ. of Technol., 2005.

[9] M. Rosignoli, "Self-launching erection machines for precast concrete bridges,” J. PCI. Vol. 55(1), pp. 36-57, 2010.

[10] K. Jung, K. Kim, C. Sim, J. Kim, "Verification of incremental launching construction safety for the ilsun bridge, the world's longest and widest prestressed concrete box girder with corrugated steel web section," J. Bridge. Eng. Vol. 16(3), pp. 453-460, 2011.

[11] B. Jacques, "Design development of steel-concrete composite bridges in France,” J. Constr. Steel Res. vol. 55(1-3), pp. 229-243, 2000.

[12] M. Virlogeux, "The viaduct over the Tarn valley near Millau-from early design to completion,” Bautechnik. Vol. 83(2), pp. 85-107, 2006.

[13] M. Buonomo, C. Servant, M. Virlogeux, J. Cremer, V. de Ville De Goyet and J. D. Forno, "The design and the construction of the Millau Viaduct,” J. Steelbridge. Millau, France, pp. 165-182. 2005.

[14] F.G. Michele, "Analysis of non-uniform torsion in curved incrementally launched bridges,” J. Eng. Str. Vol. 75, pp. 374-387, 2014.

[15] G. Wu, "Research on the construction control technology of Xiangjiang river sanchaji self-anchored suspension bridge,” Mast. Thesis. Changsha Univ. Sci. Tech. China, 2007.

[16] Z. H. Zhang, J. Y. Zhang, W. S. Hao, J. G. Dai and Y. Shen, "Hangzhou Jiangdong Bridge designed as a spatial self-anchored suspension bridge,” J. Struct. Eng. Int. 20(3), 303-307, 2010.

[17] Y.M. Bian, J. Jiang, B.X. Han, A.H. Li and G.J. Liu, "Design and Application of Hydraulic-Walking incremental Launching equipment,” J. the open Constr. Build. Technol. Vol. 7(1), pp. 1-7, 2013.

[18] M. LaViolette, T. Wipf, T. Lee, J. Bigelow, B. Phares, "Bridge construction practices using incremental launching,” Bridge Eng. Center for Trans. Res. Edu. Iowa State University Ames: Iowa, vol. 50011, 2007. 